\title{
Psychological and Pharmacological Influences in Cigarette Smoking Withdrawal: Effects of Nicotine Gum and Expectancy on Smoking Withdrawal Symptoms and Relapse
}

\author{
Andrew M. Gottlieb and Joel D. Killen \\ Center for Research in Disease Prevention \\ Stanford University School of Medicine \\ G. Alan Marlatt \\ University of Washington, Seattle \\ C. Barr Taylor \\ Laboratory for the Study of Behavioral Medicine \\ Stanford University School of Medicine
}

\begin{abstract}
To determine the relative effects of expectancy and nicotine depletion on aversive withdrawal symptoms, we gave 109 smokers attempting to quit either nicotine gum or placebo within a balanced placebo design and monitored their withdrawal symptoms and smoking for 2 weeks. Subjects who believed they were getting nicotine gum reported less physical symptoms of withdrawal, showed less arousal, and smoked fewer cigarettes during the first week of quitting when compared with those who thought they were receiving placebo gum. The actual nicotine content of gum had no effect on withdrawal or relapse.
\end{abstract}

Smokers attempting to quit often experience withdrawal symptoms that begin within a few hours of quitting and may last from 2 to 4 weeks (Shiffman, 1979). Withdrawal is an important phenomenon because many studies implicate it as a major factor in relapse (Cummings, Gordon, \& Marlatt, 1980). The extent to which psychological and physiological factors contribute to withdrawal is poorly understood. Recent doubleblind studies of nicotine gum have shown that subjects receiving nicotine gum report significantly fewer symptoms than those receiving placebo (Hughes et al., 1984). However, expectancies concerning nicotine gum may also alter withdrawal symptoms. Expectancy has been shown to affect a variety of psychological functions (Marlatt \& Rosenhow, 1980). Presumably, expectancies about nicotine gum will have their greatest impact early in the cessation process before the person has had actual experience with withdrawal symptoms and nicotine gum and, ultimately, expectancies will be altered by actual experience with nicotine gum. The present study was designed to answer the following question: What are the relative contributions of nicotine depletion versus expectancy in causing withdrawal and relapse?

\section{Method}

\section{Recruitment and Study Design}

Forty-seven men and 62 women $(N=109)$ were recruited through public advertisements. Subjects had to be between 18-70 years of age, to have smoked 20 cigarettes or more per day for more than 1 year, to

Correspondence concerning this article (and requests for an extended report of this study) should be addressed to Joel D. Killen, Center for Research in Disease Prevention, Health Research and Policy Building, Room 9, Stanford University, Stanford, California 94305. have no experience with nicotine gum, and to be able to quit for $24 \mathrm{hr}$. The mean age was 41.8 years $(S D=11.3)$. Baseline smoking rate was 32.7 cigarettes per day $(S D=12.8)$. Subjects had smoked for an average of 22.8 years $(S D=11.2)$. The mean Fagerstrom (1978) Tolerance score was 7.0 on an 11 -point scale $(S D=1.8)$.

Subjects were randomly assigned to one of four conditions in a balanced placebo design. Two groups received nicotine gum: One group was led to believe they were receiving nicotine gum (told nicotine, receive nicotine, $n=26$ ) and the other group was led to believe they were receiving placebo gum (told placebo, receive nicotine, $n=33$ ). Similarly, two groups received placebo gum: One group was led to believe they were receiving nicotine gum (told nicotine, receive placebo, $n=$ 24 ) and the other group was led to believe they were receiving placebo gum (told placebo, receive placebo, $n=26$ ).

\section{Measures}

Withdrawal symptoms were measured with a slightly modified version of the Shiffman-Jarvik Withdrawal Symptoms Scale (WSS) (Shiffman, 1979). Subjects completed the WSS first while they were still smoking (baseline) and again each day for 14 days after they attempted to quit. Subjects completed the WSS at 9:00 p.m. each day.

Subjects kept daily records of the number of pieces of gum chewed and the number of cigarettes smoked. Gum use was determined by counting the number of pieces of gum dispensed once gum had been returned. Gum counts corresponded highly with self-report data (showing $85 \%$ agreement).

Expired air carbon monoxide levels were used to validate smoker's reported smoking status. Carbon monoxide readings were measured using an Ecolyzer (Model 2000, Energetics Sciences). A cutoff level of 10 ppm was used.

Subjects rated the gum's effectiveness at helping them stay quit on a 7-point scale that they completed (a) immediately after being told their expectancy condition but before they received any gum and (b) at 7 days after they had quit. At the end of the study, subjects were asked which gum they thought they had really received-nicotine gum, placebo gum, or unsure. 


\section{Treatment Groups}

Subjects met for four weekly $1.5 \mathrm{hr}$ sessions. During Session 1, they signed consent forms, completed smoking histories, gave $\$ 50$ refundable deposits, received instruction in self-monitoring cigarette consumption, and completed the WSS as a baseline measure of smoking withdrawal symptoms. Following Session 1 , subjects were randomly assigned to the four conditions of the balanced placebo design. During the week before the second session, subjects monitored their smoking and then quit smoking completely for $24 \mathrm{hr}$ before the second session. Nicotine or placebo gum was not administered until Session 2.

In Sessions 2-4, subjects were divided into eight treatment groups of 10-15 people each, with two groups for each of the four experimental conditions. Receive-nicotine subjects received nicotine chewing gum (Nicorette, $2 \mathrm{mg}$ ). Receive-placebo subjects received a pepper-flavored placebo that was virtually identical to the Nicorette in flavor, appearance, and packaging. Subjects were instructed to chew gum whenever they felt an urge to smoke but not to exceed 30 pieces of gum per day. Compliance records were collected at Sessions 3 and 4. At the final meeting (Week 4), subjects were debriefed. In addition to gum, all subjects learned a simple muscle relaxation technique and strategies for coping with high-risk relapse situations. Therapists conducting the sessions were blind to experimental drug manipulations.

\section{Results}

\section{Manipulation Checks}

The best measure of the effectiveness of the expectancy manipulation was the subject's expectancy rating during Session 2 following assignment to experimental condition and before using any gum. The means for predicted usefulness of the gum, based on a 7-point scale, were significantly higher for the toldnicotine groups $(M=5.2, S D=1.3)$ than for the told-placebo groups $(M=2.9, S D=1.5), F(1,96)=73.50, p<.001$. Expec tancy ratings made 1 week after quitting showed that the expectancy manipulation continued to have a significant effect on gum expectancy ratings, $F(1,96)=9.87, p=.002$, with the told-nicotine groups $(M=4.8, S D=1.5)$ rating the gum more useful than the told-placebo groups ( $M=3.7, S D=1.9$ ).

Two weeks after they started to use gum, subjects were asked which gum they thought they had received. There were no significant differences in drug identification between those who received nicotine and those who received placebo.

\section{Gum Consumption}

Told-nicotine groups consumed slightly more gum per day $(M=7.7, S D=3.5)$ than did told-placebo groups $(M=6.9$. $S D=3.1$, but this difference was not significant, $F(1,101)=$ $2.83, p=.10$. There were no differences in gum consumption between the receive-nicotine groups $(M=7.3, S D=3.2)$ and the receive-placebo groups $(M=7.2, S D=3.3)$.

\section{Expectancy and Drug Effects on Smoking Rates}

Self-reported smoking data from the first and second weeks of gum use were analyzed using an Expectancy $\times$ Drug analysis of variance (ANOVA). In Week 1, there was a significant expectancy effect, $F(1,105)=4.57, p<.04$, with the told-nicotine groups smoking a mean total of 4.9 cigarettes $(S D=9.3$ ) and the told-placebo groups smoking a mean total of 11.1 cigarettes

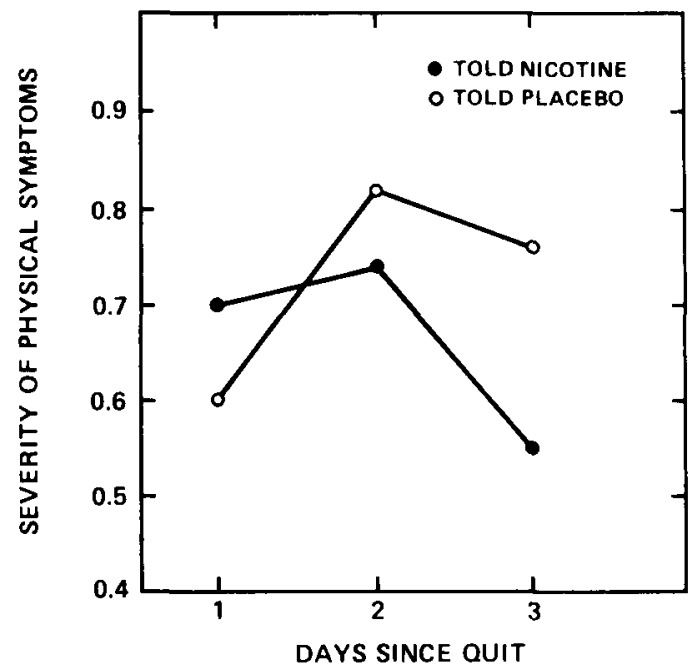

Figure 1. Severity of physical symptoms over 3 days as reported by abstainers only $(N=66)$.

$(S D=17.9)$. For Week 2 , the expectancy effect disappeared, with the told-nicotine groups smoking a mean of 11.9 cigarettes $(S D=22.9)$ and the told-placebo groups smoking 10.8 cigarettes $(S D=18.5)$. In neither week did the drug have a significant effect on smnking rates $(p>.10)$.

\section{Expectancy and Drug Effects on Abstinence}

At the end of the first week, $60 \%$ of the told-nicotine group was abstinent compared with $39 \%$ of the told-placebo group. $\chi^{2}(1, N=109)=3.98, p<.05$. The proportion of abstainers was significantly higher in the told-nicotine groups for Days 5 , 6 , and $7, \chi^{2} \mathrm{~s}(1, N=109)=4.24,5.81$, and 3.98; $p \mathrm{~s}=.04, .02$, and .05 , respectively, but not for any day after the seventh day. There were no significant differences by drug condition, with $44 \%$ of the receive-nicotine subjects and $54 \%$ of the receive-placebo subjects abstinent at 1 week. At the end of the second week, there were no significant differences in proportion of abstainers for either expectancy or drug: told nicotine $=44 \%$, told placebo $=37 \%$, get nicotine $=37 \%$, get placebo $=44 \%$.

\section{Withdrawal Symptoms}

Despite instructions to the contrary, only 44 of the 109 subjects remained completely abstinent for the full 14 days. However, 66 subjects were abstinent for Days 1-3. In order not to confound nicotine intake from gum with nicotine intake from cigarettes, only completely abstinent subjects were used to examine the effects of expectancy and nicotine on withdrawal symptoms. Therefore, analyses of withdrawal symptoms effects were based on Days $1-3$ to ensure an adequate sample size $(N=66)$. (The told-placebo, given-placebo group contained 14 subjects; the told-nicotine, given-nicotine group contained 20 subjects; the remaining two groups contained 16 subjects each.)

\section{Effects of Expectancy on Withdrawal Symptoms}

An ANOVA was performed on Expectancy $\times$ Drug $\times$ Days ( $1-$ 3). There were significant differences between the told-nicotine 
groups and the told-placebo groups only on the Physical Symptoms scale.

For physical symptoms, there was an Expectancy $\times$ Days interaction, $F(2,126)=4.25, p<.02$. The linear component of this interaction was also significant, $F(1,63)=8.19, p<.006$, indicating a difference in slope between told-nicotine and toldplacebo groups. Subjects in the told-nicotine groups showed a decrease in symptoms from Day 1 to Day 3, whereas subjects in the told-placebo groups showed an increase in symptoms (see Figure 1).

For the Stimulation scale, when only 3 days of data were analyzed, no significant differences in stimulation were found for expectancy. However, when the full 14 days of data were analyzed, using the 44 subjects who were abstinent for 14 days, a significant main effect of expectancy was found, in spite of the low power of the test, $F(1,41)=4.20, p=.05$. Told-nicotine subjects showed less stimulation $(M=2.6, S D=1.2)$ than did told-placebo subjects $(M=3.2, S D=1.1)$.

\section{Effects of Nicotine on Withdrawal Symptoms}

A Drug $\times$ Expectancy $\times$ Days ANOVA showed no significant differences between the receive-nicotine and the receive-placebo groups on any of the withdrawal scales, including Craving, Psychological Disturbance, Physical Symptoms, and Stimulation as well as the Shiffman Sum scale.

\section{Discussion}

The main finding was that expectancy affected both smoking withdrawal symptoms and smoking behavior. Those subjects expecting nicotine gum reported a significant decrease in physical symptoms, fewer stimulation symptoms, and significantly less smoking in the first week after quitting. Expectancy effects were most powerful during the first week after quitting. After 1 week, no differences were observed in smoking rates or in relapse rates. Compared with the effects of expectancy, the actual gum that subjects received, either nicotine or placebo, appeared to have no effect on either withdrawal symptoms or smoking behavior.

This finding of no drug effects on psychological symptoms contradicts results from other studies (Hughes \& Hatsukami,
1984). A likely explanation for the divergent results of this study lies in the differences between the traditional double-blind placebo design and the balanced placebo design. In the doubleblind placebo design, the subject receives a substance without instruction regarding its content and, thus, tends to introspect and to attempt to determine which substance he or she is receiving. There is evidence that in traditional double-blind studies of nicotine gum, a larger proportion of people in the nicotine group have believed they are receiving nicotine than in the placebo group (Hughes \& Krahn, 1985). This difference in beliefs means the nicotine group will have more positive expectancies for relief than the placebo group and will thus report less severe withdrawal symptoms. In contrast, our data showed no significant differences in unblinding rates by drug condition, therefore demonstrating that the balanced placebo design can control for this potential bias.

\section{References}

Cummings, C., Gordon, J. R., \& Marlatt, G. A. (1980). Relapse: Strategies of prevention and prediction. In W. R. Miller (Ed.), The addictive behaviors (pp. 291-321). Oxford, England: Pergamon Press.

Fagerstrom, K. O. (1978). Measuring degree of physical dependence to tobacco smoking with reference to individualization of treatment. Addictive Behavior, 3, 235-241.

Hughes, J. R., \& Hatsukami, D. K. (1984). Short-term effects of nicotine gum. In J. Grabowski \& S. Hall (Eds.), Pharmacological adjuncts in the treatment of tobacco dependence (National Institute on Drug Abuse Research Monograph No. 53, pp. 68-82). Washington, DC: Department of Health, Education, and Welfare.

Hughes, J. R., Hatsukami, D. K., Pickens, R. W., Krahn, D., Malin, S., \& Luknic, A. (1984). Effect of nicotine on the tobacco withdrawal syndrome. Psychopharmacology, 83, 82-87.

Hughes, J. R., \& Krahn, D. (1985). Blindness and the validity of doubleblind drug trials. Journal of Clinical Psychopharmacology, 5, 138142.

Marlatt, G. A., \& Rosenhow, D. (1980). Cognitive processes in alcohol use: Expectancy and the balanced placebo design. In N. K. Mello (Ed.), Advances in substance abuse: Behavioral and biological research (pp. 159-199). Greenwich, CN: JAI Press.

Shiffman, S. (1979). The tobacco withdrawal syndrome. In N. A. Krasnegor (Ed.), Cigarette smoking as a dependence process (National Institute on Drug Abuse Research Monograph 23, pp. 158-184). Washington, DC: Department of Health, Education, and Welfare.

Received July 9, 1986 Revision received November 20, 1986 